ISSN 0001-6002/2003/45/1/4

Acta Médica Costarricense,(C2003

Colegio de Médicos y Cirujanos

Editorial

\title{
Nutrientes como fármacos
}

La mayor variación que ha demostrado el paradigma del soporte nutricional en la última década es la tendencia a concebir algunos nutrientes como verdaderos fármacos. Es decir, ciertas substancias cuya importancia se había restringido a su valor nutritivo, se han convertido en instrumentos para manipular algunas vías metabólicas y eventualmente prevenir o hasta tratar algún padecimiento. En este sentido, el caso de los folatos es particularmente relevante debido a su valor preventivo en cardiopatía coronaria. Estudios epidemiológicos han encontrado una relación inversa entre la ingesta de folatos y el riesgo de coronariopatía, lo cual es probablemente medido por el efecto reductor de disminución de la homocisteínemia y hasta un efecto antioxidante.

Existe además evidencia aportada por Vermeulen y colaboradores (Lancet 200; 355: 517-527) que demostró que un suplemento de ácido fólico y vitamina B6 por 2 años produce una disminución significativa de la aterosclerosis subclínica indicada por electrocardiograma de esfuerzo. Otro hallazgo más dramático fue el que aportó el estudio de Schnyder et al (New England Journal of Medicine 2001; 345: 1593-1600) en el que la combinación de ácido fólico, vitamina B6 y vitamina B12 disminuyó significativamente la reestenosis luego de angioplastía coronaria a los 6 meses. Este tipo de evidencia coloca a estas substancias en un papel primordial junto con algunos fármacos antitrombóticos en el manejo integral del paciente coronario. Además, es importante hacer notar que estas nuevas modalidades de manejo vitamínico son fáciles de obtener, baratas y prácticamente libres de efectos adversos.

Por estas y otras razones más, es especialmente apropiado el título del artículo de la Msc. Suárez de Ronderos publicado en este número de Acta Médica. En efecto, se ha redescubierto el papel de los folatos en el tratamiento y prevención de enfermedades tan frecuentes con el cáncer y la cardiopatía isquémica. En esta revisión, la autora describe ampliamente los conceptos bioquímicos de esta sustancia y enumera la evidencia disponible sobre el valor de este tipo de nutrientes en la práctica clínica.

\author{
Dr. Juan Ignacio Padilla Cuadra \\ Comité de Nutrición Enteral y Perenteral \\ Hospital R. A Calderón Guardia
}

